\title{
Desempenho em Confinamento de Novilhos 5/8 Nelore - 3/8 Charolês Abatidos em Diferentes Estádios de Desenvolvimento ${ }^{1}$
}

\author{
Miguelangelo Ziegler Arboitte ${ }^{2}$, João Restle ${ }^{3}$, Dari Celestino Alves Filho ${ }^{4}$, Ivan Luiz Brondani ${ }^{5}$, \\ José Henrique Souza da Silva ${ }^{4}$, José Laerte Nörnberg ${ }^{6}$, Fernando Kuss ${ }^{7}$
}

\begin{abstract}
RESUMO - O estudo foi conduzido com o objetivo de avaliar novilhos 5/8 Nelore-3/8 Charolês quanto ao seu desempenho em confinamento até atingirem pesos de abate (P) de 425; 467 e $510 \mathrm{~kg}$. Os novilhos apresentaram, ao início do confinamento, idade média de 660 dias, peso de 361 kg e estado corporal de 2,9 pontos. A dieta oferecida, com relação volumoso:concentrado de 60:40 na base matéria seca (MS), continha 10,25\% de proteína bruta (PB), 72,18\% de nutrientes digestíveis totais (NDT) e 3,18 Mcal de energia digestível (ED)/kg de MS. O volumoso utilizado foi silagem de milho contendo 46,50\% de grãos na MS. O tempo necessário para os animais atingirem o peso de abate (P) foi de 30, 65 e 94 dias, respectivamente. Os consumos médios diários de MS, PB, NDT, ED, fibra em detergente neutro (FDN) e fibra em detergente ácido (FDA), expressos por animal, por $100 \mathrm{~kg}$ de peso vivo e por tamanho metabólico, não apresentaram relação significativa com o aumento no peso de abate. O ganho de peso médio diário (GMD) decresceu linearmente, à medida que aumentou o peso de abate (GMD=4,939-0,007P), sendo os valores médios 2,10; 1,68 e 1,56 kg, respectivamente, para os três pesos de abate. Houve relação significativa entre o peso de abate e o estado corporal final (ECF=0,658+0,008P) e o ganho médio diário em estado corporal (GEC=-2,684+0,008P). A conversão do consumo de MS, NDT, ED e PB em ganho de peso cresceu linearmente com o aumento do peso de abate (CAMS=-5,644+0,025P; CANDT=-4,074+0,018P; CAED=-17,989+0,079P; CAPB=-0,533+0,002P), indicando que a eficiência alimentar decresceu. No entanto, a conversão alimentar atingida pelos animais pode ser considerada muito boa, respectivamente, de 4,75; 5,97 e 6,75 kg de MS consumida/kg de ganho de peso.
\end{abstract}

Palavras chave: consumo, eficiência alimentar, ganho de peso, peso de abate

\section{Feedlot Performance of 5/8 Nellore-3/8 Charolais Steers Slaughtered at Different Maturity Stages}

\begin{abstract}
The objective of the experiment was to evaluate the feedlot performance of 5/8 Nellore-3/8 Charolais steers slaughtered at 425, 467 and $510 \mathrm{~kg}$. The steers presented at the beginning of the confinement average age of 660 days, live weight of $361 \mathrm{~kg}$ and body condition score of 2.9 points. The animals were fed with a 60:40 roughage:concentrate diet, containing $10.25 \%$ of crude protein (CP), $72.18 \%$ of total digestible nutrient (TDN) and 3.18 Mcal of digestible energy (DE)/ kg of DM. The time necessary for the animals reach the slaughter weight (P) was 30, 65 and 94 days, respectively. The daily average intake of DM, TDN, DE, CP, NDF and ADF expressed per animal, $100 \mathrm{~kg}$ of live weight and metabolic weight did not show a significant relationship with slaughter weight. Average daily weight gain (ADG) declined as the slaughter weight increased (ADG=4.939-0.007P), being the average values of $2.10,1.68$ and $1.56 \mathrm{~kg}$, respectively, for the three slaughter weights. There was a significant relationship between slaughter weight and final body condition score $(\mathrm{FBC}=0.658+0.008 \mathrm{P})$ and daily gain in $\mathrm{BC}(\mathrm{DGBC}=-2.684+0.008 \mathrm{P})$. The food conversion of the DM,TDN,DE and CP intake into weight gain, increased linearly as the slaughter weight increased $(\mathrm{CDM}=-5.644+0.025 \mathrm{P}$; CTDN=-4.074+0.0187P; CDE=-17.925+0.079P; $\mathrm{CCP}=-0.578+0.003 \mathrm{P}$ ), showing that the feed efficiency declined. However, the food conversion can be considered satisfactory, respectively, 4.75, 5.97 and $6.75 \mathrm{~kg}$ of DM consumed/kg of weight gain.
\end{abstract}

Key Words: feed conversion, feed intake, slaughter weight, weight gain

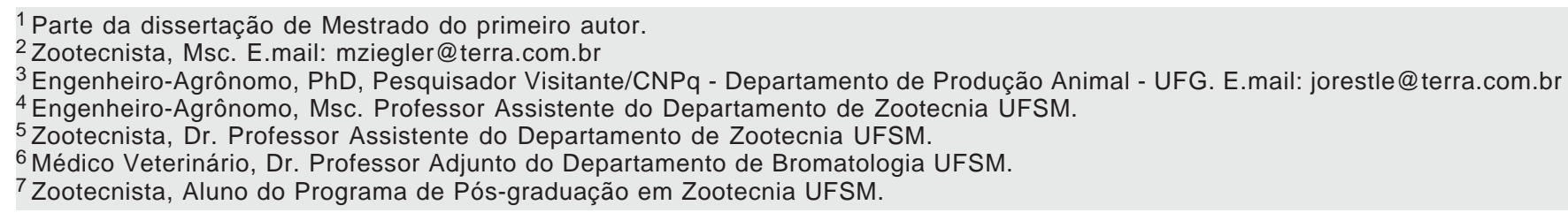




\section{Introdução}

Produzir novilhos para abate entre 20 e 24 meses em confinamento é uma alternativa utilizada a vários anos no Brasil. No entanto, nos últimos anos a lucratividade tem caído, principalmente em função dos altos custos da alimentação, que são responsáveis por aproximadamente $70 \%$ do custo total do confinamento (Restle \& Vaz, 1999). Períodos longos de confinamento, causados por baixo peso inicial dos animais; baixo ganho de peso, motivados por fatores genéticos e/ou baixa concentração energética da dieta; e pelo peso de abate elevado, resultam em baixa eficiência econômica do processo.

Para animais jovens, os frigoríficos exigem peso mínimo de carcaça de $225 \mathrm{~kg}$ (dando preferência aos animais mais pesados) e cobertura mínima de gordura de $3 \mathrm{~mm}$. A terminação de bovinos com peso elevado influencia o desempenho, uma vez que, à medida que aumenta o tempo de alimentação em confinamento, ocorre redução na eficiência de transformação de alimentos em ganho de peso, em função da demanda de energia para mantença e alterações na composição do ganho de peso, pela maior intensidade de deposição de gordura (Costa et al., 2002a,b).

Segundo Owens et al. (1993), os tecidos do corpo desenvolvem-se em estádios de crescimento específicos, começando com o tecido nervoso, em seguida, o tecido ósseo, o tecido muscular e, por último, o tecido adiposo. O peso de abate afeta a proporção de músculo, gordura e ossos na carcaça, pois estes tecidos, geralmente, apresentam taxas de crescimento diferentes, que se alteram durante a vida do animal (Leme et al., 2000). Portanto, para determinação do peso de abate, além do desempenho no confinamento, devem-se considerar também as características da carcaça e da carne.

Restle et al. (1996) relatam que para atingir o grau de acabamento desejado os animais devem ser alimentados por um período mais longo, já que a gordura é um tecido de deposição tardia e aumenta proporcionalmente com o avanço da idade e o peso do bovino. Segundo Restle et al. (1999), aumentar o grau de acabamento da carcaça pode representar redução no lucro do produtor, pois o tecido adiposo requer mais alimentos para ser depositado. Além disso, a gordura em excesso é removida da carcaça no frigorífico, sem remuneração para o produtor.

O presente trabalho foi conduzido com o objetivo de avaliar o desempenho em confinamento de novilhos 5/8
Nelore - 3/8 Charolês, confinados a partir dos 21 meses de idade e abatidos em três diferentes pesos, 425, 467 e 510 kg.

\section{Material e Métodos}

O presente estudo foi conduzido no período de agosto a novembro de 2001 no Setor de Bovinocultura de Corte do Departamento de Zootecnia da Universidade Federal de Santa Maria, situada na Depressão Central do Rio Grande do Sul, com coordenadas $29^{\circ} 42^{\prime}$ de latitude Sul e $54^{\circ} 42^{\prime}$ de longitude Oeste e 96 metros de altitude. Segundo classificação de Köppen, citado por Moreno (1961), o clima predominante é do tipo "Cfa2", subtropical úmido com estiagem no verão, com temperatura média mensal máxima superior a $22^{\circ} \mathrm{C}$ e mínima entre 3 e $18^{\circ} \mathrm{C}$. A precipitação média anual varia de 1300 a $1800 \mathrm{~mm}$. Durante o período experimental, a temperatura média mensal mínima foi de $11,6^{\circ} \mathrm{C}$ no mês de agosto e a máxima, de $28^{\circ} \mathrm{C}$ no mês de novembro. A precipitação durante o período experimental variou de 68,5 (agosto) a 237,1 mm (setembro) e a umidade relativa do ar, de 73 a $81,6 \%$.

Os tratamentos foram os três pesos de abate pretendidos (420, 460 e $500 \mathrm{~kg}$ ), sendo os pesos de abate reais 425, 467 e $510 \mathrm{~kg}$, respectivamente. Foram utilizados 18 novilhos 5/8 Nelore - 3/8 Charolês contemporâneos, provenientes do mesmo rebanho, com idade média de 660 dias, peso médio de 361 kg e estado corporal médio de 2,91 pontos (escala de 1 a 5). Os bovinos foram distribuídos em nove grupos de dois animais equilibrados por peso, distribuídos aleatoriamente nos tratamentos.

Os animais tiveram livre acesso à água e ao alimento, fornecido duas vezes ao dia (8 e 17h). Antes do arraçoamento da manhã, eram retiradas as sobras dos comedouros, sendo estas pesadas para medir o consumo do dia anterior; após a pesagem regulava-se a oferta de alimento em $10 \%$ superior ao consumido no dia anterior. A dieta (Tabela 1) foi calculada segundo o NRC (1996), objetivando ganho de peso médio diário de 1,6 kg/animal/dia, estimando-se consumo de 2,5 kg de MS/100 kg PV. A silagem de milho utilizada foi de alta qualidade, com $46,50 \%$ de grãos na massa ensilada. A dieta continha 10,25\% PB e 3,18 Mcal de ED/kg de MS.

Após o período de adaptação às instalações e à dieta (14 dias), e ao final de cada subperíodo experimental (21 dias), foram realizadas pesagens, antecedidas de jejum prévio de sólidos de 14 horas.

\section{R. Bras. Zootec., v.33, n.4, p.947-958, 2004}


À medida que os animais atingiram o peso próximo ao pretendido, eram pesados com intervalos menores, em função da projeção do peso de abate, com base no ganho de peso médio diário do período anterior.

Semanalmente, foram coletadas amostras dos ingredientes que compunham a dieta, para posterior análise laboratorial (Tabela 2).

Foram determinados os teores de matéria seca e matéria orgânica, de proteína bruta, extrato etéreo, fibra bruta, extrativo não-nitrogenado e cinzas pelo método AOAC (1984), digestibilidade in vitro da matéria seca e matéria orgânica (Tilley \& Terry, 1963), teor de fibra em detergente neutro (FDN) corrigida para cinzas e amido e fibra em detergente ácido (FDA) (Van Soest \& Wine, 1967).

Para obtenção da concentração de NDT, utilizou-se a fórmula: \%NDT $=-72,93+4,675 *(\mathrm{FB})-1,28 *(\mathrm{EE})+$ $0,497 *(\mathrm{~PB})-0,044 *(\mathrm{FB})^{2}-0,76 *(\mathrm{E} \mathrm{E})^{2}-$ $0,039 *(\mathrm{FB}) *(\mathrm{ENN})+0,087 *(\mathrm{EE}) *(\mathrm{ENN})-$ $0,152 *(\mathrm{EE}) *(\mathrm{~PB})+0,74 *(\mathrm{EE})^{2 *}(\mathrm{~PB})$, sugerida pela Latin American Tables of Feed Composition (1974). A energia digestível (ED) foi calculada segundo o NRC (2000), em que $1 \mathrm{~kg}$ NDT=4,4 Mcal de ED/kg de MS. A concentração de energia metabolizável (EM), energia líquida de mantença (Elm) e energia líquida de ganho (Elg) da dieta foram calculadas a partir da ED, usando as equações do NRC (2000). As exigências de Elg e Elm foram calculadas utilizando as equações sugeridas pelo NRC (1996), em que: $\mathrm{Elm}=0,077 * \mathrm{PV}^{0,75}$ e Elg $=0,0562 * \mathrm{PV}^{0,75 *} \mathrm{GMD}^{1,097}$.

Tabela 1 - Composição da dieta, base matéria seca Table 1 - Diet composition, dry matter basis

\begin{tabular}{lc}
\hline $\begin{array}{l}\text { Ingredientes } \\
\text { Ingredients }\end{array}$ & $\%$ \\
\hline $\begin{array}{l}\text { Silagem de milho } \\
\text { Corn silage }\end{array}$ & 60,00 \\
$\begin{array}{l}\text { Farelo de trigo } \\
\text { Wheat bran }\end{array}$ & 28,24 \\
$\begin{array}{l}\text { Sorgo } \\
\text { Sorghum }\end{array}$ & 10,07 \\
$\begin{array}{l}\text { Uréia } \\
\text { Urea }\end{array}$ & 0,17 \\
Calcário calcítico \\
$\begin{array}{l}\text { Limestone } \\
\text { NaCl }\end{array}$ \\
$\begin{array}{l}\text { NaCl } \\
\text { Rumensin }\end{array}$
\end{tabular}

${ }^{1}$ Elanco.

R. Bras. Zootec., v.33, n.4, p.947-958, 2004
O delineamento experimental utilizado foi inteiramente casualizado com três tratamentos e três repetições, compostas por um lote de dois animais. Os dados foram submetidos à análise de regressão por intermédio do programa estatístico SAS (1997).

$\mathrm{O}$ modelo estatístico empregado foi:

$$
\mathrm{Y}_{\mathrm{ij}}=\mathrm{B}_{0}+\mathrm{B}_{1} \mathrm{P}_{i j}+\mathrm{B}_{2} \mathrm{P}^{2}{ }_{i j}+\mathrm{E}_{i j}
$$

em que $\mathrm{Y}_{\mathrm{ij}}=$ variáveis dependentes; $\mathrm{B} 0$; $\mathrm{B} 1 ; \mathrm{B} 2$ = Parâmetros da equação a serem estimados; $\mathrm{P} i j=$ peso ao abate na repetição $\mathrm{j}$ do tratamento $\mathrm{i}$; $\mathrm{E}_{i j}=$ erro experimental da observação ij, $\operatorname{NID}\left(0, \sigma^{2}\right)$

Tabela 2 - Teores (\%) de matéria seca (MS), proteina bruta (PB), extrato etéreo (EE), fibra bruta (FB), extrativo não nitrogenado (ENN), cinzas (Cinzas), fibra em detergente neutro (FDN), fibra em detergente ácido (FDA), digestibilidade in vitro da matéria seca (DIVMS), digestibilidade in vitro da matéria orgânica (DIVMO) e nutrientes digestíveis totais (NDT) dos componentes da dieta

Table 2 - Contents (\%) of dry matter (DM), ), crude protein $(C P)$, ether extract $(E E)$, crude fiber $(C F)$, nitrogenfree extract (NFE) ashes, neutral detergent fiber (NDF), acid detergent fiber (ADF), "in vitro" dry matter digestibility (IVDMD), in vitro organic matter digestibility (IVOMD) and total digestible nutrients (TDN) of the diet components

\begin{tabular}{|c|c|c|c|}
\hline $\begin{array}{l}\text { Composição } \\
\text { Composition }\end{array}$ & $\begin{array}{c}\text { Silagem } \\
\text { Silage }\end{array}$ & $\begin{array}{c}\text { F. trigo } \\
\text { Wheat bran }\end{array}$ & $\begin{array}{c}\text { Sorgo } \\
\text { Sorghum }\end{array}$ \\
\hline$\overline{\mathrm{MS}}$ & 39,05 & 91,80 & 92,22 \\
\hline$D M$ & & & \\
\hline $\begin{array}{l}\text { PB } \\
C P\end{array}$ & 6,21 & 16,13 & 6,93 \\
\hline $\begin{array}{l}\mathrm{EE} \\
\mathrm{EE}\end{array}$ & 2,05 & 3,88 & 1,01 \\
\hline $\begin{array}{l}\text { FB } \\
C F\end{array}$ & 22,41 & 9,97 & 1,42 \\
\hline $\begin{array}{l}\text { ENN } \\
N F E\end{array}$ & 68,50 & 68,99 & 89,11 \\
\hline $\begin{array}{l}\text { Cinzas } \\
\text { Ashes }\end{array}$ & 1,24 & 1,64 & 1,85 \\
\hline $\begin{array}{l}\mathrm{FDN}^{1} \\
N D F^{1}\end{array}$ & 39,03 & 37,45 & 17,98 \\
\hline $\begin{array}{l}\mathrm{FDN}^{2} \\
N D F^{2}\end{array}$ & 45,56 & 37,72 & 32,10 \\
\hline $\begin{array}{l}\text { FDA } \\
A D F\end{array}$ & 22,27 & 12,53 & 3,63 \\
\hline $\begin{array}{l}\text { DIVMS } \\
\text { IVDMD }\end{array}$ & 58,64 & 70,31 & 81,14 \\
\hline $\begin{array}{l}\text { DIVMO } \\
\text { IVOMD }\end{array}$ & 59,11 & 70,34 & 81,52 \\
\hline $\begin{array}{l}\text { NDT } \\
T D N\end{array}$ & 69,32 & 76,02 & 80,37 \\
\hline
\end{tabular}

${ }^{1}$ FDN corrigida para cinzas e amido.

${ }_{1}^{1}$ NDF corrected for ashes and starch.

2 FDN Não corrigido.

${ }^{2}$ Not corrected NDF. 


\section{Resultados e Discussão}

Na Tabela 3, constam os valores médios para ganho de peso diário (GMD), estado corporal e número de dias necessários para atingir o peso de abate.

Conforme pode ser verificado, o GMD decresceu linearmente $(\mathrm{P}=0,0198)$, à medida que aumentou o peso de abate. Para cada kg a mais no peso de abate o GMD decresceu 0,007 kg, quando estimado pela equação de regressão.

Alterações no GMD em função do peso de abate ou número de dias em confinamento são relatados na literatura. Zinn et al. (1970) estudaram o desempenho de novilhos Hereford, com intervalos de abate a cada 30 dias, iniciando com peso de abate de 235 até o peso de abate de $443 \mathrm{~kg}$, alimentados inicialmente com $40 \%$ de concentrado, aumentando gradualmente até $60 \%$. Estes autores verificaram que o GMD aumentou até $392 \mathrm{~kg}$, declinando após, em comportamento quadrático. Contudo, no presente estudo, a queda no GMD em relação ao aumento do peso foi linear.
O GMD de 2,1 kg dos animais abatidos com $425 \mathrm{~kg}$ foi elevado. Embora os animais tenham passado por um período de adaptação à dieta durante 14 dias, parte deste ganho pode ser atribuída ao ganho compensatório, já que estes apresentavam peso inicial de $362 \mathrm{~kg}$ e estado corporal de 2,92, muito próximo do estado médio (3), o que indica bom desenvolvimento muscular, mas pouca deposição de gordura subcutânea. Além disso, o elevado potencial genético dos animais para ganho de peso pôde ser expresso, já que a dieta apresentava elevada densidade energética (3,18 Mcal de ED/kg de MS), com $40 \%$ de concentrado associado à silagem de milho de alta qualidade (46,5\% de grãos na MS e 69,32\% de NDT). O período de confinamento para os animais atingirem o peso de abate especificado foi curto (30 dias), em função do elevado GMD e peso inicial de $362 \mathrm{~kg}$. Os animais deste tratamento já alcançavam no início do confinamento $85 \%$ do peso final. Períodos curtos de confinamento são economicamente importantes, pois representam menor consumo de energia de mantença,

Tabela 3 - Médias para dias em confinamento, peso vivo inicial (PVI), ganho de peso médio diário (GMD) e total (GPV), condição corporal inicial (ECI) e final (ECF), ganho diário (GDEC) e total de condição corporal (GEC), de acordo com o peso de abate Table 3 - Means for days on feed, initial weight (IW), average daily (ADG) and total weight gain (TWG), initial (IBC) and final body condition (FBC), daily (DBCG) and total body condition gain (BCG) according to slaughter weight

\begin{tabular}{|c|c|c|c|c|}
\hline \multirow[t]{2}{*}{$\begin{array}{l}\text { Variável } \\
\text { Variable }\end{array}$} & \multicolumn{3}{|c|}{$\begin{array}{l}\text { Peso de abate } \\
\text { Slaughter weight }\end{array}$} & \multirow[t]{2}{*}{$\begin{array}{c}\text { Equação de regressão } \\
\text { Regression equation }\end{array}$} \\
\hline & P425 & P467 & P510 & \\
\hline $\begin{array}{l}\text { Dias em } \\
\text { confinamento } \\
\text { Days on feed }\end{array}$ & 30 & 65 & 94 & - \\
\hline $\begin{array}{l}\text { PVI, kg } \\
I W, k g\end{array}$ & $362 \pm 49,63$ & $358 \pm 38,02$ & $363 \pm 33,70$ & $\hat{\mathrm{Y}}=361 \pm 38,58$ \\
\hline $\begin{array}{l}\text { GMD, kg } \\
A D G, k g\end{array}$ & $2,10 \pm 0,56$ & $1,68 \pm 0,21$ & $1,56 \pm 0,24$ & $\hat{\mathrm{Y}}=4,939-0,007 \mathrm{~Pa}$ \\
\hline $\begin{array}{l}\text { GPV, kg } \\
T W G, k g\end{array}$ & $63,1 \pm 16,73$ & $109,0 \pm 13,93$ & $147,3 \pm 22,66$ & $\hat{\mathrm{Y}}=-80,167+1,059 \mathrm{~Pb}$ \\
\hline $\begin{array}{l}\mathrm{ECI}^{1} \\
\mathrm{IBC}\end{array}$ & $2,92 \pm 0,10$ & $2,95 \pm 0,10$ & $2,84 \pm 0,13$ & $\hat{\mathrm{Y}}=2,90 \pm 0,11$ \\
\hline $\begin{array}{l}\mathrm{ECF}^{1} \\
\mathrm{FBC}\end{array}$ & $3,77 \pm 0,12$ & $4,26 \pm 0,18$ & $4,38 \pm 0,17$ & $\hat{\mathrm{Y}}=0,658+0,008 \mathrm{Pc}$ \\
\hline $\begin{array}{l}\text { GDEC } \\
D B C G\end{array}$ & $0,029 \pm 0,004$ & $0,020 \pm 0,003$ & $0,016 \pm 0,002$ & $\hat{\mathrm{Y}}=0,092-0,001 \mathrm{Pd}$ \\
\hline $\begin{array}{l}\text { GEC } \\
B C G\end{array}$ & $0,86 \pm 0,11$ & $1,31 \pm 0,17$ & $1,54 \pm 0,20$ & $\hat{\mathrm{Y}}=-2,684+0,008 \mathrm{Pe}$ \\
\hline
\end{tabular}

${ }^{a} R^{2}=0,81, P=0,0198 ;{ }^{b} R^{2}=0,20, P=0,0198 ;{ }^{c} R^{2}=0,68, P=0,0001 ;{ }^{d} R^{2}=0,75, P=0,0001 ;{ }^{e} R^{2}=0,75, P=0,0001$.

${ }^{1}$ Estado corporal $-1=$ muito magro; $2=$ magro; $3=$ médio; $4=$ gordo 5 = muito gordo.

${ }^{1}$ Body condition - 1= extremely thin; 2=thin; 3= average; $4=$ fat; $5=$ extremely fat. 
maior rotatividade de animais e maior giro de capital.

As carcaças dos animais abatidos com $425 \mathrm{~kg}$ apresentaram $232 \mathrm{~kg}$ e espessura de gordura subcutânea de 3,57 mm, levemente acima do mínimo exigido pelos frigoríficos, ou seja, $225 \mathrm{~kg}$ de carcaça e $3 \mathrm{~mm}$ de gordura de cobertura.

O estado corporal em 30 dias de confinamento passou de 2,92 para 3,77, muito próximo do estado gordo (4) (Tabela 3). Esta rápida melhoria no estado corporal pode ser atribuída principalmente à concentração energética da dieta, utilizada para manutenção e crescimento, incluindo a deposição de gordura. Uma vez atendidas as exigências de manutenção e o crescimento, sobretudo, muscular e dos órgãos internos, o organismo passa a depositar o excesso da energia consumida sob a forma de gordura. Portanto, quanto maior a concentração energética da dieta ingerida, maior é a quantidade de energia disponível para deposição de tecido adiposo e mais rápido também será a deposição de gordura subcutânea, que vai conferir o adequado grau de acabamento à carcaça.

O GMD dos animais abatidos com $467 \mathrm{~kg}$ foi de $1,68 \mathrm{~kg}$. A diferença no GMD entre o P425 e o P467 foi de $0,425 \mathrm{~kg}$, representando queda de $20 \%$. Esta desaceleração no GMD pode ser explicada, principalmente, pela maior demanda de energia requerida para manutenção (NRC, 1996) e composição de ganho. Verifica-se que o estado corporal, que avalia subjetivamente a deposição de gordura subcutânea aumentou de 3,77 para 4,26 pontos, acima do estado corporal gordo (4). O ganho em estado corporal no período de confinamento dos animais $\mathrm{P} 425$ foi de 0,86 pontos, enquanto nos animais P467 este ganho foi de 1,31 pontos ( $52 \%$ a mais).

Medindo a espessura de gordura subcutânea depositada sobre a carcaça, verificou-se aumento de $77 \%$, para os animais P467 (6,33 mm), quando comparado aos P425 (3,57 mm) (Arboitte et al., 2004). Portanto, os animais abatidos com maior peso utilizaram maior quantidade de energia de mantença e obtiveram ganhos de peso com maior conteúdo energético e, como a dieta alimentar continha o mesmo teor de energia, esta não foi suficiente para manter o mesmo ritmo de ganho de peso que os animais do tratamento P425.

Os animais abatidos com $510 \mathrm{~kg}$ apresentaram GMD de 1,56 kg, 7\% inferior aos abatidos com $467 \mathrm{~kg}$ e menor que o verificado quando peso de abate aumentou de 425 para 467 kg (Tabela 3). Isto comprova que os animais ainda estavam em crescimento, o que pode ser confirmado pelo comprimento de carcaça, que foi de 123, 126 e 129 cm, respectivamente, para os três pesos de abate (Arboitte et al., 2004). A queda observada no GMD, ao aumentar o peso de abate de 467 para $510 \mathrm{~kg}$, reflete pequena melhora no estado corporal, que passou de 4,26 para 4,38 pontos.

Oganho de estado corporal passou de 1,31 para 1,51 pontos, representando incremento de $15 \%$, inferior aos $52 \%$ verificados quando o peso de abate passou de 425 para $467 \mathrm{~kg}$. A menor intensidade de deposição de gordura, avaliada pelo estado corporal foi confirmada pela espessura de gordura subcutânea, que passou de 6,33 para 7,33 mm (Arboitte etal., 2004), correspondendo a aumento de $16 \%$.

Comparando o GMD entre os animais P425 e P510, verificou-se queda de $0,450 \mathrm{~kg}$, representando uma redução de 26\%. Embora os animais abatidos com 510 kg tenham mostrado redução no GMD, este ainda é alto, quando se leva em consideração que eram castrados. O bom desempenho foi reflexo da qualidade da dieta e do elevado potencial genético dos animais para ganho de peso.

Menores diferenças para GMD, comparado aos verificados no presente experimento, frente ao aumento do peso de abate, são relatados com novilhos de raças mais tardias como o Charolês (Barber et al., 1981; Restle et al., 1997), enquanto outros autores (Cruz et al., 1996; Jorge et al., 1998) não verificaram diferença no GMD quando elevaram o peso de abate de animais não-castrados. Raças tardias e animais não-castrados acumulam gordura com mais intensidade, tendo pesos mais elevados e, por conseguinte, ganhos menos energéticos e o mesmo ritmo de ganho de peso por períodos mais prolongados que animais de raças precoces ou castrados.

O GMD dos três grupos de abate foi, em média, de $1,78 \mathrm{~kg}$, superior ao GMD relatado em todos os trabalhos de pesquisa revisados, inclusive naqueles em que foram utilizados animais não castrados. Costa et al. (2002b) utilizaram animais da raça precoce, Red Angus, para produção de novilhos superprecoce, alimentados com dieta contendo $50 \%$ de concentrado e 2,8 Mcal de ED/kg de MS, abatidos com 340, 370, 400 e $430 \mathrm{~kg}$, e verificaram que numericamente o GMD decresceu com o aumento do peso de abate, porém a regressão não foi significativa, sendo a queda no GMD entre os pesos extremos de $12,8 \%$, inferior à verificada no presente trabalho. Estudando o comportamento do desempenho de novilhos da raça

R. Bras. Zootec., v.33, n.4, p.947-958, 2004 
Aberdeen Angus alimentados com dietas variando em EM de 2,72 e 2,96 Mcal/kg de MS e abatidos com 409, 472 ou $534 \mathrm{~kg}$, Barber et al. (1981) verificaram que o GMD decresceu significativamente com o aumento no peso de abate, representando redução de $26 \%$ do peso de abate, de 409 para $534 \mathrm{~kg}$. Esta queda foi igual aos $26 \%$ verificados entre os grupos P425 e P510 kg.

O estado corporal final e o ganho de estado corporal aumentaram linearmente, à medida que se elevou o peso de abate $(\mathrm{P}<0,0001)$. Estes aumentos, estimados pela equação de regressão, foram 0,008 e 0,009 pontos para cada kg a mais de ganho de peso, respectivamente comportamento esperado neste tipo de estudo, em decorrência da deposição de gordura subcutânea, resultando em melhor acabamento nas carcaças dos animais com o aumento no peso de abate.

Os animais foram abatidos com estado corporal de médio a gordo, sendo este de 3,77; 4,26 e 4,38 pontos, respectivamente, para os pesos de abate de 425, 467 e $510 \mathrm{~kg}$. O estado corporal correlacionou-se positivamente com espessura de gordura $(r=0,76$; $\mathrm{P}=0,0003)$, porcentagem de gordura na carcaça $(\mathrm{r}=0,63 ; \mathrm{P}=0,053)$ e ganho total de peso vivo $(\mathrm{r}=0,85$; $\mathrm{P}=0,0001)$. Foi estimado pela equação de regressão que a carcaça dos novilhos atingiria cobertura mínima gordura de $3 \mathrm{~mm}$, exigida pelos frigoríficos, com peso de abate de $425 \mathrm{~kg}$ e estado corporal de 3,69 pontos.

Ganhos de estado corporal mais acentuados, de 1,$36 ; 1,78 ; 1,80$ e 2,26 pontos, foram verificados em animais Red Angus abatidos com 340, 370, 400 e 430 kg de peso, respectivamente, tendo alta correlação com espessura de gordura e porcentagem de gordura na carcaça (Costa et al., 2002b).
Na Tabela 4, constam os resultados referentes ao consumo médio diário de matéria seca por animal (CMSD), por $100 \mathrm{~kg}$ de peso vivo (CMSPV) e por unidade de tamanho metabólico (CMSTM).

O consumo, expresso nas diferentes formas não foi influenciado pelo peso de abate. Segundo Hicks et al. (1990), o principal fator que afeta o CMSD de novilhos confinados é o peso no início do confinamento, pois, à medida que o peso inicial aumenta, o CMSD é incrementado. Relação direta entre o peso inicial e CMSD também foi relatada por Townsend (1991) e Quadros (1994), com animais de diferentes idades e pesos iniciais, e Bail et al. (2000), com animais de mesma idade e pesos iniciais diferentes. No presente experimento, o peso inicial foi similar para os três pesos de abate, não sendo esperadas grandes diferenças no CMSD, principalmente, se for considerado que os animais ainda estavam crescendo, mesmo no peso de abate mais elevado, conforme comentado anteriormente. Outros autores também verificaram que o peso de abate não influenciou o CMSD (Van Koevering et al. 1995; Cruz et al., 1996; Restle et al., 1997).

O CMSPV foi estatisticamente similar entre os grupos de abate P425, P467 e P510; 2,53; 2,41 e $2,43 \%$, respectivamente, com média de $2,46 \%$, próximo do valor estimado para cálculo da dieta, segundo o NRC (1984). Restle et al. (1997) também não verificaram diferença significativa no CMSPV nos pesos de abate de 421, 461 e $495 \mathrm{~kg}$ de novilhos Charolês, quando comparados pela análise de variância. No entanto, quando os dados foram submetidos a análise de regressão, o CMSPV decresceu linearmente (Y=2,8033-0,125X). Galvão et al. (1991),

Tabela 4 - Médias diárias de consumo médio de matéria seca por animal (CMSD), por $100 \mathrm{~kg}$ de peso vivo (CMSPV) e por tamanho metabólico (CMSTM), de acordo com o peso de abate

Table 4 - Means for average daily dry matter intake per animal(DMI), per $100 \mathrm{~kg}$ of live weight (DMILW) and per metabolic weight (DMIMW), according to the slaughter weight

\begin{tabular}{lcccc}
\hline $\begin{array}{l}\text { Variável } \\
\text { Variable }\end{array}$ & \multicolumn{3}{c}{$\begin{array}{c}\text { Peso de abate } \\
\text { Slaughter weight }\end{array}$} & $\begin{array}{c}\text { Médias } \\
\text { Means }\end{array}$ \\
\cline { 2 - 4 } & $\mathrm{P} 425$ & $\mathrm{P} 467$ & $\mathrm{P} 510$ & \\
\hline $\begin{array}{l}\text { CMSD, kg } \\
\text { DMI, } \mathrm{kg}\end{array}$ & $9,97 \pm 0,58$ & $9,93 \pm 0,32$ & $10,61 \pm 0,94$ & $\hat{\mathrm{Y}}=10,17 \pm 0,66$ \\
$\begin{array}{l}\text { CMSPV, kg } \\
\text { DMILW, } \mathrm{kg}\end{array}$ & $2,53 \pm 0,19$ & $2,41 \pm 0,08$ & $2,43 \pm 0,17$ & $\hat{\mathrm{Y}}=2,46 \pm 0,15$ \\
$\begin{array}{l}\text { CMSTM, g } \\
\text { DMIMW, } g\end{array}$ & $112,79 \pm 7,54$ & $108,50 \pm 3,63$ & $111,02 \pm 8,47$ & $\hat{\mathrm{Y}}=110,77 \pm 6,24$ \\
\hline
\end{tabular}

R. Bras. Zootec., v.33, n.4, p.947-958, 2004 
utilizando animais não-castrados Nelore e suas cruzas com Limousin ou Marchigiana, abatidos com pesos equivalentes a 90, 100 e $110 \%$ do peso adulto, não encontraram diferença significativa no CMSPV .

O CMSTM não diferiu entre os pesos de abate, com média de 110,77 g. CMSTM verificados no presente trabalho são próximos aos relatados por Restle et al. (1997) 117,4; 111,3 e 111,2 g de CMSTM para novilhos com 421, 461 e 495 kg de PV. Galvão et al. (1991) relataram valores de CMSTM maiores, ao abaterem machos não-castrados com 90, 100 e $110 \%$ do peso adulto $(119,6 ; 119,3$ e 122 , 2 g, respectivamente), não encontrando diferença significativa entre os pesos de abate. Costa et al. (2002b), alimentando novilhos superprecoce Red Angus até pesos de abate de 340, 370, 400 e $430 \mathrm{~kg}$ PV, relataram valores estatisticamente semelhantes entre si de 102, 99, 97 e $94 \mathrm{~g} / \mathrm{kg} \mathrm{PV}^{0,75}$, respectivamente.

Na Tabela 5 constam as médias para consumo médio diário de energia digestível (CED) por animal (CEDD), por $100 \mathrm{~kg}$ de peso vivo (CEDPV) e por unidade de tamanho metabólico (CEDTM).

O CED, expresso nas diferentes formas, não foi significativamente afetado pelo peso de abate, acompanhando a tendência do CMS (Tabela 4). Numericamente, os animais abatidos com 510 kg consumiram $6,48 \%$ mais ED/dia que os abatidos com $425 \mathrm{~kg}$. No entanto, esta diferença no CED não foi suficiente para aqueles manterem o mesmo ritmo no GMD que os abatidos com $425 \mathrm{~kg}$, em função da composição do ganho e do aumento no requerimento de energia de mantença.

Segundo o NRC (2000), o tipo racial influencia na exigência líquida de mantença, preconizando que animais Bos indicus e mestiços Bos taurus x Bos indicus necessitam, respectivamente, de 10 e 5\% menos de energia líquida de mantença que os animais Bos taurus. A conseqüência disto seria maior disponibilidade de energia líquida para ganho em animais mestiços e zebuínos. Esta diferença na exigência de Elm pode ser um dos fatores que contribuem positivamente para o GMD elevado dos animais.

Na Tabela 6, constam os valores médios para o consumo diário de proteína bruta (CPB) por animal (CPBD), por $100 \mathrm{~kg}$ de peso vivo (CPBPV) e por unidade de tamanho metabólico (CPBTM) que não foram afetados pelo peso de abate e que seguiram a mesma tendência do CMS.

O CPBD para os três pesos de abate foi levemente superior ao recomendado pelo NRC (1984) para GMD de 1,6 kg, sendo que a média do GMD dos três pesos de abate foi de $1,78 \mathrm{~kg}$. Porte et al (2000) relatam que a relação entre energia metabolizável e proteína da dieta é fator determinante para os animais manterem elevado ganho de peso. Esses autores constataram que o tratamento com maior relação

Tabela 5 - Consumo médio diário de energia digestível por animal (CEDD), por 100 $\mathrm{kg}$ de peso vivo (CEDPV), por unidade de tamanho metabólico (CEDTM), consumo de energia líquida de mantença (CEIm) e de ganho por animal (CElg), de acordo com o peso de abate

Table 5 - Means for average daily digestible energy intake per animal (DEI), per $100 \mathrm{~kg}$ live weight (DEIP),per metabolic weight (DEIM), intake of net energy for maintenance (Nem) and gain (Neg), according to slaughter weight

\begin{tabular}{lcccc}
\hline Variável & \multicolumn{3}{c}{$\begin{array}{c}\text { Peso de abate } \\
\text { Slaughter weight }\end{array}$} & $\begin{array}{c}\text { Equação de regressão } \\
\text { Regression equation }\end{array}$ \\
\cline { 2 - 4 } & P425 & P467 & P510 & \\
\hline $\begin{array}{l}\text { CEDD, Mcal } \\
\text { DEI, Mcal }\end{array}$ & $31,65 \pm 1,85$ & $31,55 \pm 1,01$ & $33,70 \pm 2,99$ & $\hat{\mathrm{Y}}=32,30 \pm 2,11$ \\
$\begin{array}{l}\text { CEDPV, Mcal } \\
\text { DEIP, Mcal }\end{array}$ & $8,04 \pm 0,60$ & $7,25 \pm 0,27$ & $7,71 \pm 0,58$ & $\hat{\mathrm{Y}}=7,80 \pm 0,47$ \\
$\begin{array}{l}\text { CEDTM, kcal } \\
\text { DEIM, } \text { cal }\end{array}$ & $358,22 \pm 23,94$ & $344,60 \pm 11,52$ & $352,61 \pm 26,90$ & $\hat{\mathrm{Y}}=351,81 \pm 19,81$ \\
CElm, Mcal & $6,81 \pm 0,27$ & $7,05 \pm 0,06$ & $7,35 \pm 0,10$ & $\hat{\mathrm{Y}}=3,939+0,007 \mathrm{~Pa}$ \\
$\begin{array}{l}\text { Nem, Mcal } \\
\text { CElg, Mcal }\end{array}$ & $6,45 \pm 0,64$ & $6,26 \pm 0,34$ & $6,80 \pm 1,20$ & $\hat{\mathrm{Y}}=6,50 \pm 0,65$ \\
Neg, Mcal & & & & \\
\hline
\end{tabular}

$\mathrm{a}^{2}=0,7012, P=0,0048$.

R. Bras. Zootec., v.33, n.4, p.947-958, 2004 
entre energia metabolizável e proteína bruta $(0,20)$ apresentou maior GMD (1,681 kg), comparando com os demais tratamentos, em que as relações foram de $0,13(0,96 \mathrm{~kg}) ; 0,15$ (1,3 kg) e 0,17 (1,55 kg). A dieta oferecida forneceu $10,25 \%$ de $\mathrm{PB}$ e $2,60 \mathrm{Mcal} / \mathrm{kg}$ de MS de EM, representando relação energia/proteína de 0,25 , podendo ser considerada alta se comparada com o trabalho anteriormente citado, o que contribuiu para manter os altos GMD.

Constam na Tabela 7 os valores médios para o consumo diário de fibra em detergente ácido (CFDA) e fibra em detergente neutro (CFDN), por animal (CFDND), (CFDAD), por $100 \mathrm{~kg}$ peso vivo (CFDNP), (CFDAP) e por unidade de tamanho metabólico (CFDNM), (CFDAM), que não foram afetados pelo peso de abate.

Verificou-se que o CFDN acompanhou o CMS, não sofrendo alteração em função do peso de abate. Costa et al. (2002b) observaram que o CFDNP e CFDAP decresceram à medida que o

Tabela 6 - Consumo médio diário de proteína bruta por animal (CPBD), por $100 \mathrm{~kg}$ de PV (CPBPV) e por unidade de tamanho metabólico (CPBTM), de acordo com o peso de abate

Table 6 - Means for average daily crude protein intake per animal(CPI), per $100 \mathrm{~kg}$ of live weight (CPIP), per metabolic weight (CPIM), according to slaughter weight

\begin{tabular}{lcccc}
\hline $\begin{array}{l}\text { Variável } \\
\text { Variable }\end{array}$ & \multicolumn{3}{c}{$\begin{array}{c}\text { Peso de abate } \\
\text { Slaughter weight }\end{array}$} & $\begin{array}{c}\text { Médias } \\
\text { Means }\end{array}$ \\
\cline { 2 - 4 } & $\mathrm{P} 425$ & $\mathrm{P} 467$ & $\mathrm{P} 510$ & \\
\hline $\begin{array}{l}\text { CPBD, kg } \\
\text { CPI, } \mathrm{kg}\end{array}$ & $1,02 \pm 0,06$ & $1,02 \pm 0,03$ & $1,09 \pm 0,1$ & $\hat{\mathrm{Y}}=1,04 \pm 0,07$ \\
$\begin{array}{l}\text { CPBPV, kg } \\
\text { CPIP, } \mathrm{kg}\end{array}$ & $0,26 \pm 0,07$ & $0,25 \pm 0,01$ & $0,25 \pm 0,18$ & \\
$\begin{array}{l}\text { CPBTM, } \\
\text { CPIM, } g\end{array}$ & $11,56 \pm 0,77$ & $11,12 \pm 0,37$ & $11,38 \pm 0,87$ & $\hat{\mathrm{Y}}=0,252 \pm 0,01$ \\
\hline
\end{tabular}

Tabela 7 - Consumo médio diário por animal de fibra em detergente neutro (CFDND), por $100 \mathrm{~kg}$ de PV (CFDNP), por unidade de tamanho metabólico (CFDNM), consumo médio diário de fibra em detergente ácido (CFDAD), por $100 \mathrm{~kg}$ de peso vivo (CFDAP), por unidade de tamanho metabólico (CFDAM), de acordo com peso de abate

Table 7 - Means for average daily neutral detergent fiber intake per animal(NDFI), per $100 \mathrm{~kg}$ of live weight (NDFP), per metabolic weight (NDFIM), acid detergent fiber intake per animal (ADFI), per $100 \mathrm{~kg}$ of live weight (ADFP), per metabolic weight (ADFIM), according to slaughter weight

\begin{tabular}{lcccc}
\hline $\begin{array}{l}\text { Variável } \\
\text { Variable }\end{array}$ & \multicolumn{3}{c}{$\begin{array}{c}\text { Peso de abate } \\
\text { Slaughter weight }\end{array}$} & $\begin{array}{c}\text { Médias } \\
\text { Means }\end{array}$ \\
\cline { 2 - 4 } $\begin{array}{l}\text { CFDND, kg } \\
\text { NDFI, } \mathrm{kg}\end{array}$ & $\mathrm{P} 425$ & $\mathrm{P} 467$ & $\mathrm{P} 510$ & \\
$\begin{array}{l}\text { CFDNP, kg } \\
\text { NDFI, } \mathrm{kg}\end{array}$ & $0,937 \pm 0,07$ & $0,890 \pm 0,03$ & $0,898 \pm 0,898$ & $\hat{\mathrm{Y}}=0,908 \pm 0,05$ \\
$\begin{array}{l}\text { CFDNM, g } \\
\text { NDFIM, } g\end{array}$ & $41,72 \pm 2,79$ & $40,13 \pm 1,34$ & $41,07 \pm 3,13$ & $\hat{\mathrm{Y}}=40,97 \pm 2,30$ \\
$\begin{array}{l}\text { CFDAD, } \mathrm{kg} \\
\text { ADFI, } \mathrm{kg}\end{array}$ & $1,83 \pm 0,11$ & $1,82 \pm 0,06$ & $1,85 \pm 0,17$ & $\hat{\mathrm{Y}}=1,87 \pm 0,12$ \\
$\begin{array}{l}\text { CFDAP, } \mathrm{kg} \\
\text { ADFI, } \mathrm{kg}\end{array}$ & $0,465 \pm 0,03$ & $0,442 \pm 0,02$ & $0,446 \pm 0,03$ & $\hat{\mathrm{Y}}=0,451 \pm 0,03$ \\
$\begin{array}{l}\text { CFDAM, g } \\
\text { ADFIM, } g\end{array}$ & $20,70 \pm 1,38$ & $19,91 \pm 0,67$ & $20,37 \pm 1,55$ & $\hat{\mathrm{Y}}=20,33 \pm 1,14$ \\
\hline
\end{tabular}

R. Bras. Zootec., v.33, n.4, p.947-958, 2004 
peso de abate aumentou, causado principalmente pelo decréscimo de CMSP. Estes autores relatam CFDNP maiores aos deste trabalho, embora tenham usado maior teor de concentrado na dieta. A explicação para este comportamento está na qualidade da silagem de milho utilizada no presente experimento, que apresentou maior concentração de grãos (46,5\%) e menor teor de FDN (39,03\%), inferior ao de $41 \%$, considerado pelo NRC (1996) como silagem de boa qualidade. A qualidade da silagem utilizada foi um dos principais fatores responsáveis pelo elevado GMD dos novilhos. Cappelle et al. (2001), ao estimarem o valor energético a partir de características químicas e bromatológicas dos alimentos, concluíram que o valor energético aumenta em função do aumento da digestibilidade de MS e da digestibilidade da MO e reduz com a elevação dos teores de FDN e FDA.

As médias referentes à conversão alimentar de MS (CAMS), NDT (CANDT), ED (CAED) e PB (CAPB) em ganho de peso são apresentadas na Tabela 8.

A conversão alimentar aumentou linearmente com o aumento do peso de abate, indicando que a eficiência de transformar alimentos em ganho de peso decresceu. Segundo estimativa obtida pela equação de regressão, para cada $\mathrm{kg}$ a mais no peso de abate, os animais necessitaram de $24,9 \mathrm{~g}$ a mais de matéria seca por kg de ganho de peso. Os animais abatidos com $425 \mathrm{~kg}$ consumiram 20,4 e 29,6\% a menos de alimento por kg de ganho de peso que os abatidos com 467 e $510 \mathrm{~kg}$, respectivamente. Isto tem implicação de ordem prática e econômica muito importante para o sistema de produção.

Trabalhando com animais Red Angus para produção de novilhos superprecoces, Costa et al. (2002b) abateram os animais com 340, 370, 400 e $430 \mathrm{~kg}$, resultando em CAMS de 5,09; 5,35; 5,55 e 6,04, respectivamente. Já a CAED, citada na mesma ordem, foi de 13,$94 ; 14,54 ; 15,11$ e 16,60. A queda na eficiência de transformação da MS em ganho de peso foi menos acentuada, tendo o CAMS elevado $10 \mathrm{~g}$ para cada kg de aumento no peso de abate, contra os 24,9 g verificados no presente experimento. Já a CAED, embora inferior à do presente experimento, apresentou maior incremento, sendo de $284 \mathrm{kcal}$ para cada $\mathrm{kg}$ a mais no peso de abate, contra os 79 kcal verificados nesta pesquisa.

Conversão alimentar superior à do presente experimento e sem aumento significativo frente ao aumento do peso de abate é relatada por Restle et al. (1997), para novilhos Charolês abatidos com 421, 461 e $495 \mathrm{~kg}$, sendo esta, respectivamente, de 8,7; 8,2; e 9,3. Galvão et al (1991) em animais Nelore e mestiços Nelore-Marchigiana e Limousin-Nelore não-castrados abatidos com peso equivalente a 90,100 e $110 \%$ do peso adulto, verificaram que a CAMS foi similar (8,37; 8,89 e 9,17, respectivamente). Cruz et al.

Tabela 8 - Médias para conversão alimentar de matéria seca MS, kg MS/kg de ganho de peso (CAMS), nutrientes digestíveis totais, $\mathrm{kg}$ de NDT/kg de ganho de peso (CANDT), energia digestível $\mathrm{Mcal} / \mathrm{kg}$ de ganho de peso (CAED), proteína bruta, $\mathrm{kg} \mathrm{PB/kg}$ de ganho de peso (CAPB), de acordo com peso de abate

Table 8 - Means for conversion of dry matter, $\mathrm{kg}$ DM/kg of weight gain (CDM), total digestible nutrient, $\mathrm{kg} T D N / \mathrm{kg}$ of weight gain (CTDN), digestible energy Mcal/ $\mathrm{kg}$ of weight gain (CDE) and crude protein, $\mathrm{kg} C P / \mathrm{kg}$ of weight gain (CCP), according to slaughter weight

\begin{tabular}{lcccc}
\hline $\begin{array}{l}\text { Variáveis } \\
\text { Variable }\end{array}$ & \multicolumn{3}{c}{$\begin{array}{c}\text { Peso de abate } \\
\text { Slaughter weight }\end{array}$} & $\begin{array}{c}\text { Médias } \\
\text { Means }\end{array}$ \\
\cline { 2 - 4 } $\begin{array}{lcccc}\text { CAMS } \\
\text { CDM }\end{array}$ & $4,75 \pm 0,14$ & $5,97 \pm 0,59$ & $6,75 \pm 0,65$ & $\hat{\mathrm{Y}}=-5,644+0,025 \mathrm{~Pa}$ \\
$\begin{array}{l}\text { CANDT } \\
\text { CTDN }\end{array}$ & $3,43 \pm 0,10$ & $4,31 \pm 0,43$ & $4,87 \pm 0,47$ & $\hat{\mathrm{Y}}=-4,074+0,0187 \mathrm{~Pa}$ \\
$\begin{array}{l}\text { CAED } \\
\text { CDE }\end{array}$ & $15,15 \pm 0,44$ & $19,04 \pm 1,88$ & $21,51 \pm 2,06$ & $\hat{\mathrm{Y}}=-17,989+0,079 \mathrm{~Pa}$ \\
$\begin{array}{l}\text { CAPB } \\
\text { CCP }\end{array}$ & $0,449 \pm 0,01$ & $0,564 \pm 0,06$ & $0,627 \pm 0,07$ & $\hat{\mathrm{Y}}=-0,533+0,002 \mathrm{~Pa}$ \\
\hline
\end{tabular}

a $R^{2}=0,7802 \quad P=0,0016$

R. Bras. Zootec., v.33, n.4, p.947-958, 2004 
(1996), em animais Nelore e mestiços de raças continentais com Nelore, não-castrados e abatidos com 400, 440 e $480 \mathrm{~kg}$, constataram CAMS de 8,6; 8,8 e 9,6, respectivamente.

A queda na eficiência alimentar foi conseqüência do decréscimo no GMD com o aumento do peso de abate, já que o CMS apenas evoluiu levemente quando o peso de abate passou de 425 para $510 \mathrm{~kg}$. A redução na eficiência alimentar foi causada pelo aumento da Elm (Tabela 5) e pela composição de ganho de peso, que passou a ser mais energética à medida que o peso de abate aumentou.

A conversão alimentar é a característica mais importante sob o ponto de vista prático, já que influencia diretamente a relação entre o que é gasto em forma de alimentos e o que é retornado na forma de ganho de peso. Melhorar a eficiência alimentar é fundamental no confinamento, pois está diretamente relacionado com o aspecto econômico. Restle et al. (2000) relatam que, no processo de terminação de bovinos, devem-se considerar a eficiência biológica e a eficiência econômica. Segundo esses autores, a eficiência econômica, além de ser influenciada diretamente pela eficiência biológica, considera os custos da dieta e o valor do produto final, que é o ganho de peso vivo ou de carcaça.

A conversão alimentar de 4,75 para os animais abatidos com $425 \mathrm{~kg}$ pode ser considerada excelente, melhor inclusive que a relatada por Costa et al. (2002b), em novilhos superprecoces com gordura de acabamento similar.

Também nos animais abatidos com 467 kg, a conversão alimentar foi abaixo de 6, considerada boa. Nos novilhos abatidos com 510 kg, a conversão alimentar ficou abaixo de 7 e pode ser considerada boa, pois foi melhor que a da maioria dos trabalhos revisados e conduzidos no país e mesmo no exterior. O desempenho, em termos de CAMS e CAED, foi conseqüência direta do elevado GMD, causado principalmente pelo potencial genético dos animais e pela concentração energética da dieta. A CAPB aumentou com o peso de abate dos animais, passando de 0,449 para 0,627 , sendo melhor que a relatada por Eifert (2000), de 0,878, e por Costa et al. (2002b), de 0,675; 0,$703 ; 0,731$ e 0,802 , respectivamente, para os pesos de abate de 340; 370; 400 e $430 \mathrm{~kg}$.
É provável que tenha ocorrido ganho compensatório na fase inicial do confinamento, provavelmente nos animais abatidos com $425 \mathrm{~kg}$. Segundo o NRC (1996), quando os animais estão em fase de ganho compensatório, o CMS aumenta e a exigência de mantença decresce, resultando em melhor eficiência de uso da energia metabolizável para ganho em energia corporal. No entanto, cabe ressaltar que os animais no início do confinamento apresentaram peso elevado e estado corporal próximo a 3, indicando desenvolvimento uniforme. Na maioria dos trabalhos de pesquisa conduzidos no país, o ganho compensatório ocorre em maior ou menor grau, dependendo do peso inicial, principalmente quando a terminação ocorre com mais de 20-24 meses de idade.

Na Tabela 9, constam os consumos totais de MS, NDT, ED, EM, Elm, Elg e PB, que se elevaram linearmente frente ao aumento do peso de abate.

O consumo total destes nutrientes dos animais abatidos com $510 \mathrm{~kg}$ foi 3,34 e 1,54 vezes superior aos abatidos com 425 e $467 \mathrm{~kg}$, enquanto o dos bovinos abatidos com $467 \mathrm{~kg}$ foi 2,16 vezes superior aos abatidos com $425 \mathrm{~kg}$. Considerando que os animais abatidos aos $425 \mathrm{~kg}$ atingiram o peso de carcaça mínimo de 232,5 kg (acima dos $225 \mathrm{~kg}$ ) e gordura de cobertura de $3,57 \mathrm{~mm}$, levemente acima dos $3 \mathrm{~mm}$ exigidos pelos frigoríficos para novilhos jovens, seria possível terminar 3,34 vezes mais animais em comparação com o alimento gasto para alimentar os animais abatidos aos $510 \mathrm{~kg}$. A conseqüência direta seria melhor eficiência econômica do processo de confinamento representado, principalmente, pela melhor conversão alimentar (29,6\% menos alimento por $\mathrm{kg}$ de ganho de peso) e maior giro de capital. Isto é particularmente importante em épocas em que os custos dos alimentos são elevados em relsação ao preço do boi gordo.

Cabe ressaltar que atualmente a terminação em confinamento é uma técnica com baixa margem de lucro. Isto pode ser alterado com o uso de animais que, no início do confinamento, apresentam peso mais elevado e alto potencial genético para ganho de peso. Podem-se utilizar também dietas com concentração energética adequada, ressaltando que a qualidade do volumoso é muito importante para conferir aos animais elevado ganho de peso e adequada deposição de gordura na carcaça. 
Tabela 9 - Médias para consumo individual total de matéria seca (CMS), nutrientes digestíveis totais (CNDT), energia digestível (CED), energia metabolizável (CEM), energia líquida de mantença (CEIm) e ganho (CElg) e proteína bruta (CPB), de acordo com peso de abate

Table 9 - Means for total individual consumption of dry matter (DMI), total digestible nutrients (TNDI), digestibible energy (DEI), metabolizable energy (MEI), net energy for maintenance (NemI), net energy for growth (Negl) and crude protein,(CPI), according to slaugther weight

\begin{tabular}{|c|c|c|c|c|}
\hline \multirow[t]{2}{*}{$\begin{array}{l}\text { Variável } \\
\text { Variable }\end{array}$} & \multicolumn{3}{|c|}{$\begin{array}{l}\text { Peso de abate } \\
\text { Slaughter weight }\end{array}$} & \multirow[t]{2}{*}{$\begin{array}{l}\text { Equação de regressão } \\
\text { Regression equation }\end{array}$} \\
\hline & P 425 & P467 & P 510 & \\
\hline $\begin{array}{l}\text { CMS, kg } \\
D M I, k g\end{array}$ & $299,00 \pm 17,51$ & $645,66 \pm 20,67$ & $997,53 \pm 88,51$ & $\hat{\mathrm{Y}}=-3.369,138+8,732 \mathrm{~Pa}$ \\
\hline $\begin{array}{l}\text { CNDT, kg } \\
T D N I, k g\end{array}$ & $215,82 \pm 12,64$ & $466,04 \pm 14,04$ & $720,02 \pm 63,89$ & $\hat{\mathrm{Y}}=-2.431,844+6,302 \mathrm{~Pa}$ \\
\hline $\begin{array}{l}\text { CED, Mcal } \\
\text { DEI, Mcal }\end{array}$ & $949,60 \pm 55,63$ & $2.050,59 \pm 65,64$ & $3.168,07 \pm 281,11$ & $\hat{\mathrm{Y}}=-10.700+27,731 \mathrm{~Pa}$ \\
\hline $\begin{array}{l}\text { CEM, Mcal } \\
\text { MEI, Mcal }\end{array}$ & $778,67 \pm 45,61$ & $1.681,48 \pm 53,83$ & $2.597,82 \pm 230,51$ & $\hat{\mathrm{Y}}=-8.774,092+22,739 \mathrm{~Pa}$ \\
\hline $\begin{array}{l}\text { CElm, Mcal } \\
\text { NemI, Mcal }\end{array}$ & $204,30 \pm 8,19$ & $458,24 \pm 6,26$ & $691,39 \pm 9,31$ & $\hat{\mathrm{Y}}=-2.349,378+6,088 \mathrm{~Pb}$ \\
\hline $\begin{array}{l}\text { CElg, Mcal } \\
\text { NegI, Mcal }\end{array}$ & $193,53 \pm 19,21$ & $407,03 \pm 22,39$ & $639,43 \pm 90,35$ & $\hat{\mathrm{Y}}=-2 \cdot 150,600+5,578 \mathrm{Pc}$ \\
\hline $\begin{array}{l}\mathrm{CPB} \\
\mathrm{CPI}\end{array}$ & $30,65 \pm 1,79$ & $66,18 \pm 2,12$ & $102,25 \pm 9,07$ & $\hat{\mathrm{Y}}=-345,337+0,895 \mathrm{~Pa}$ \\
\hline
\end{tabular}

a $R^{2}=0,98, P=0,0001 ;{ }^{b} R^{2}=0,99, P=0,0001 ;{ }^{c} R^{2}=0,9423, P=0,0001$.

\section{Conclusões}

Os consumos médios diários de matéria seca, energia e proteína não foram afetados pelo aumento do peso de abate.

Recomenda-se o peso de abate de $425 \mathrm{~kg}$, em razão do maior ganho de peso médio diário e da melhor eficiência de transformar alimento em ganho de peso.

Com a quantidade de alimento gasto para terminar os novilhos mais pesados, daria para terminar 3,34 vezes mais animais com menor peso em período de tempo $68 \%$ mais curto.

\section{Literatura Citada}

ARBOITTE, M.Z.; RESTLE, J.; ALVES FILHO, D.C. et al. Características da carcaça de novilhos 5/8 Nelore 3/8 Charolês abatidos com diferentes estádios de desenvolvimento. Revista Brasileira de Zootecnia, v.33, n.4, p.969-977, 2004.

ASSOCIATION OF ANALITIC CHEMIST - AOAC. Official methods of analysis. 14.ed. Washington, D.C.: 1984. 1141p.

BAIL, C.A.T.; BRONDANI, I.L.; RESTLE, J. Níveis de concentrado na fase de terminação em confinamento para novilhos previamente mantidos em pastagem nativa ou cultivada. Ciência Rural, v.30, n.1, p.151-157, 2000.

BARBER, K.A.; WILSON, L. L.; ZIEGLER, J.H. et al. Charolais and Angus steers slaughtered at equal percentages of mature cow weight. I. Effects of slaughter weight and diet energy density on carcass traits. Journal of Animal Science, v.52, n.2, p.218-231, 1981.

CAPPELLE, E.R.; VALADARES FILHO, S.C.V.; SILVA, J.F.C. et al. Estimativas do valor energético a partir de características químicas e bromatológicas dos alimentos. Revista Brasileira de Zootecnia, v.30, n.6, p.1837-1856, 2001.

COSTA, E.C.; RESTLE, J.; VAZ, F.N. et al. Características da carcaça de novilhos Red Angus superprecoces abatidos com diferentes pesos. Revista Brasileira de Zootecnia, v.31 suplemento, p.417-428, 2002a.

COSTA, E.C.; RESTLE, J.; VAZ, F.N. et al. Desempenho de novilhos Red Angus superprecoce, confinados e abatido com diferentes pesos. Revista Brasileira de Zootecnia, v.31, n.1, p.129-138, 2002b.

CRUZ, G.M.; TULLIO, R.R.; ESTEVES, S.N. et al. Desempenho em confinamento e características de carcaça de machos cruzados abatidos com diferentes pesos, Para produção do bovino jovem. In: REUNIÃO ANUAL DA SOCIEDADE BRASILEIRA DE ZOOTECNIA, 33., 1996, Fortaleza. Anais... Fortaleza: Sociedade Brasileira de Zootecnia, 1996.

EIFERT, E.C. Silagem de sorgo e de triticale associadas a níveis de concentrado para alimentação de terneiros de corte desmamados precocemente. Santa Maria: Universidade Federal de Santa Maria, 2000. 150p. Dissertação (Mestrado em Zootecnia) - Universidade Federal de Santa Maria, 2000.

GALVÃO, J.G.; FONTES, C.A.A.; PIRES, C.C. et al. Ganho de peso, consumo e conversão alimentar em bovinos não castrados, de três grupos raciais, abatidos em diferentes estágios de maturidade (estudo I). Revista Brasileira de Zootecnia, v.20, p.494-501, 1991.

HICKS,R.B.; OWENS,F.N; GILL, D.R. et al. Dry matter intake

R. Bras. Zootec., v.33, n.4, p.947-958, 2004 
by feedlot beef steers: Influence of initial weight, time on feed and season of received in yard. Journal of Animal Science, v.68, p.254-265, 1990.

JORGE, A.M.; FONTES, C.A.A.; PULINO, M.F. et al. Desempenho produtivo de animais de quatro Raças Zebuínas, abatidos em três estádios de maturidade. 1 Ganho de peso e de carcaça e eficiência de ganho. Revista Brasileira de Zootecnia, v.27, n.4, p.766-769, 1998.

LATIN AMERICAN TABLES OF FEED COMPOSITION. Florida: University of Florida, 1974. p.11-16.

LEME, P.R.; BOIN, C.; MARGARIDO, R.C.C. et al. Desempenho em confinamento e características de carcaça de bovinos machos de diferentes cruzamentos abatidos em três faixas de peso. Revista Brasileira de Zootecnia, v.29, n.6, p.23472353, 2000 (suplemento).

MORENO, J.A. Clima do Rio Grande do Sul. Porto Alegre: Secretaria da Agricultura, 1961. 41p.

NATIONAL RESEARCH COUNCIL - NRC. Nutrient requirements of domestic animals. 6.rev.ed. Washington, D.C.: National Academy Press, 1984. 90p.

NATIONAL RESEARCH COUNCIL - NRC. Nutrient requirements of domestic animals. 7.rev.ed. Washington, D.C.: National Academy Press, 1996. 242p.

NATIONAL RESEARCH COUNCIL - NRC. Nutrient requirements of domestic animals. 8.rev.ed. Washington, D.C.: National Academy Press, 2000. 280p.

OWENS, F.N.; DUBESKI, P.; HANSON, C.F. Factors that alter the growth and development of ruminants. Journal of Animal Science, v.71, p.3138-3150, 1993.

PORTE, E.; MANTEROLA, H.; CERDA, D. Effecto de distintos niveles de energia en la dieta, sobre el comportamento productivo de novillos Hereford en crianza-engorda. Avances en Producción Animal, v.25, n.1 y 2, 2000.

QUADROS, A.R.B. Avaliação de duas fontes de proteína na alimentação de bovinos de diferentes idades, em regime de confinamento. Santa Maria: Universidade Federal de Santa Maria, 1994. 122p. Dissertação (Mestrado em Zootecnia) - Universidade Federal de Santa Maria, 1994.

RESTLE, J.; KEPLIN, L.A.S.; VAZ, F.N. et al. Qualidade da carne de novilhos Charolês confinados e abatidos com diferentes pesos. Ciência Rural, v.26, n.3, p.463-466, 1996.

RESTLE, J.; KEPLIN, L.A.S; VAZ, F.N. Desempenho em confinamento de novilhos Charolês terminados com diferentes pesos. Pesquisa Agropecuária Brasileira, v.32, n.8, p.857-860, 1997.
RESTLE, J.; VAZ, F.N. Confinamento de bovinos definidos e cruzados. In: LOBATO, J.F.P.; BARCELLOS, J.O.J.; KESSELER, A.M. (Eds.). Produção de bovinos de corte. Porto Alegre: EDIPUCRS, 1999. p.141-168.

RESTLE, J.; VAZ, F.N.; QUADROS, A.R.B. Características de carcaça e da carne de novilhos de diferentes genótipos de Hereford x Nelore. Revista Brasileira de Zootecnia, v.28, n.6, p.1245-1251, 1999.

RESTLE, J.; ALVES FILHO, D.C.; NEUMMAN, M. Eficiência na terminação de bovinos de corte. In: RESTLE, J. (Ed.) Eficiência na produção de bovinos de corte. Santa Maria: Universidade Federal de Santa Maria, 2000. p.277-303.

STATISTICAL ANALYSES SYSTEM - SAS. SAS/STAT. User's guide: statistics. 4.ed. Cary: 1997. 943p.

TILLEY, J.M.; TERRY, R.A. A two-estage technique for the in vitro digestion of forage crops. Journal British Grassland Society, v.18, p.104-111, 1963.

TOWSEND, M.R. Desempenho em confinamento de diferentes categorias animais e características de carcaça e da carne de novilhos e vacas. Santa Maria: Universidade Federal de Santa Maria, 1991. 191p. Dissertação (Mestrado em Zootecnia) - Universidade Federal de Santa Maria, 1991.

Van KOEVERING, M.T.; GILL, D.R.; OWENS, F.N. et al. Effect of time on feed on performance of feedlot steers, carcass characteristics, and tenderness and composition of longissimus muscle. Journal of Animal Science, v.73, p.21-28, 1995.

Van SOEST, P.J.; WINE, R.H. Use of detergents in analysis of fibrous feeds. IV. Determinations of plant cell-wall constituents. Journal of Association Official Analysis Chemists, v.50, p.50, 1967.

ZINN, D.W; DURRHAN, R.M.; HEDRICK, H.B. Feedlot and carcass grade characteristics of steers and heifers as influenced by days on feed. Journal of Animal Science, v.31, p.302-306, 1970. 